\title{
Haematological response in experimental human Plasmodium falciparum and Plasmodium vivax malaria
}

Stephen D. Woolley 1,2,3, Louise Marquart ${ }^{1}$, John Woodford ${ }^{1,5}$, Stephan Chalon ${ }^{4}$, Joerg J. Moehrle ${ }^{4}$, James S. McCarthy ${ }^{1,6}$ and Bridget E. Barber ${ }^{1 *}$ (D)

\begin{abstract}
Background: Malaria-associated anaemia, arising from symptomatic, asymptomatic and submicroscopic infections, is a significant cause of morbidity worldwide. Induced blood stage malaria volunteer infection studies (IBSM-VIS) provide a unique opportunity to evaluate the haematological response to early Plasmodium falciparum and Plasmodium vivax infection.
\end{abstract}

Methods: This study was an analysis of the haemoglobin, red cell counts, and parasitaemia data from 315 participants enrolled in IBSM-VIS between 2012 and 2019, including 269 participants inoculated with the 3D7 strain of $P$. falciparum (Pf3D7), 15 with an artemisinin-resistant P. falciparum strain (PfK13) and 46 with P. vivax. Factors associated with the fractional fall in haemoglobin (Hb-FF) were evaluated, and the malaria-attributable erythrocyte loss after accounting for phlebotomy-related losses was estimated. The relative contribution of parasitized erythrocytes to the malaria-attributable erythrocyte loss was also estimated.

Results: The median peak parasitaemia prior to treatment was 10,277 parasites/ml (IQR 3566-27,815), 71,427 parasites/ml [IQR 33,236-180,213], and 34,840 parasites/ml (IQR 13,302-77,064) in participants inoculated with Pf3D7, PfK13, and P. vivax, respectively. The median Hb-FF was 10.3\% (IQR 7.8-13.3), 14.8\% (IQR 11.8-15.9) and 11.7\% (IQR 8.9-14.5) in those inoculated with Pf3D7, PfK13 and P. vivax, respectively, with the haemoglobin nadir occurring a median 12 (IQR 5-21), 15 (IQR 7-22), and 8 (IQR 7-15) days following inoculation. In participants inoculated with P. falciparum, recrudescence was associated with a greater Hb-FF, while in those with P. vivax, the Hb-FF was associated with a higher pre-treatment parasitaemia and later day of anti-malarial treatment. After accounting for phlebotomyrelated blood losses, the estimated Hb-FF was 4.1\% (IQR 3.1-5.3), 7.2\% (IQR 5.8-7.8), and 4.9\% (IQR 3.7-6.1) in participants inoculated with Pf3D7, PfK13, and P. vivax, respectively. Parasitized erythrocytes were estimated to account for $0.015 \%$ (IQR 0.006-0.06), 0.128\% (IQR 0.068-0.616) and 0.022\% (IQR 0.008-0.082) of the malaria-attributable erythrocyte loss in participants inoculated with Pf3D7, PfK13, and P. vivax, respectively.

Conclusion: Early experimental P. falciparum and P. vivax infection resulted in a small but significant fall in haemoglobin despite parasitaemia only just at the level of microscopic detection. Loss of parasitized erythrocytes accounted for $<0.2 \%$ of the total malaria-attributable haemoglobin loss.

Keywords: Plasmodium falciparum, Induced blood-stage malaria, CHMI, VIS, Malaria, Anaemia

\footnotetext{
*Correspondence: bridget.barber@qimrberghofer.edu.au

1 QIMR Berghofer Medical Research Institute, 300 Herston Road, Brisbane, QLD 4006, Australia
}

Full list of author information is available at the end of the article

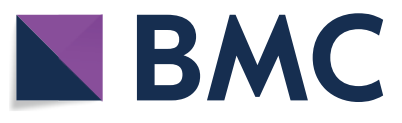

(c) The Author(s) 2021. Open Access This article is licensed under a Creative Commons Attribution 4.0 International License, which permits use, sharing, adaptation, distribution and reproduction in any medium or format, as long as you give appropriate credit to the original author(s) and the source, provide a link to the Creative Commons licence, and indicate if changes were made. The images or other third party material in this article are included in the article's Creative Commons licence, unless indicated otherwise in a credit line to the material. If material is not included in the article's Creative Commons licence and your intended use is not permitted by statutory regulation or exceeds the permitted use, you will need to obtain permission directly from the copyright holder. To view a copy of this licence, visit http://creativecommons.org/licenses/by/4.0/. The Creative Commons Public Domain Dedication waiver (http://creativeco mmons.org/publicdomain/zero/1.0/) applies to the data made available in this article, unless otherwise stated in a credit line to the data. 


\section{Background}

Malaria remains a major cause of mortality and morbidity worldwide, with 229 million cases and 409,000 reported deaths in 2019 [1]. Furthermore, it is likely that the disruption of services due to the current COVID19 pandemic may significantly increase the number of malaria cases and malaria deaths [2]. Malaria-associated anaemia is one of the most important complications of malaria [3-9]. Hospital-based studies have demonstrated that severe anaemia can occur in patients infected with Plasmodium falciparum, Plasmodium vivax and Plasmodium malariae, and in all three species increases the risk of death [3]. More recently, cross-sectional community surveys have demonstrated that asymptomatic and submicroscopic infections are also associated with a high risk of anaemia, contributing significantly to the overall burden of malaria-associated anaemia $[10,11]$.

Malaria-associated anaemia is multi-factorial. Although occurring in part due to the rupture of parasitized red blood cells (RBCs), the major contributor to malaria is the loss of unparasitized RBCs, with previous studies estimating that the ratio of the loss of parasitized to unparasitized RBCs is $1: 8$ in P. falciparum $[12,13]$ and 1:34 in P. vivax [14]. Potential contributors to this loss of unparasitized cells include increased free radical damage [15], the loss of erythrocyte surface complement regulatory proteins [16] and the production of anti-phosphatidylserine antibodies [17]. Dyserythropoiesis caused by bone marrow suppression secondary to the direct effects of the parasites as well as the effect of cytokines [18-21], and inflammation-induced iron deficiency [22], are other key contributors to malaria-associated anaemia. Shortened red cell lifespan following artesunate therapy [23] may also be contributory.

The induced blood-stage malaria (IBSM) volunteer infection model developed at QIMR Berghofer in 1995 has recently assumed a key role in anti-malarial drug development [24]. To date, over 400 participants have been enrolled in these studies at QIMR Berghofer, including 342 inoculated with the fully sensitive $P$. falciparum 3D7 strain, 15 with the K13 artemisinin resistant stain, and 46 with $P$. vivax. In these studies, parasitaemia is closely monitored with a highly sensitive quantitative PCR targeting the 18S rRNA gene, and frequent blood sampling occurs to monitor haematological parameters throughout the course of infection. Therefore, these studies provide a unique opportunity to investigate the haematological response that occurs in early $P$. falciparum and $P$. vivax blood-stage infection.

In this study, haematology data from 26 IBSM volunteer infection studies undertaken at QIMR Berghofer over the last ten years were analysed, in order to describe the haematological response to $P$. falciparum and $P$. vivax infection, and to evaluate factors associated with the fractional fall in haemoglobin. The haematological and parasitaemia data were also used to estimate the relative contribution of the loss of parasitized and unparasitized cells to the total malaria-attributable haemoglobin loss.

\section{Methods \\ Study design and participants}

Data were retrieved from the records of 315 participants enrolled in 26 IBSM studies conducted at QIMR Berghofer between 2012 and 2019 (Additional file 1: Table S1). Details of these studies have been published previously [25-47]. In brief, malaria-naïve participants were included if they were aged 18-55 years, had no significant co-morbidities or concurrent illness, and had haematology and biochemistry results at baseline that were within the protocol specified range. Participants were inoculated (day 0) with red blood cells parasitized with either P. falciparum 3D7 (Pf3D7; $\mathrm{n}=254$ ), an artemisinin-resistant strain of $P$. falciparum with a defined mutation on the K13 propeller gene (PfK13; $n=15$ ), or P. vivax $(\mathrm{n}=46)$. Parasitaemia was closely monitored at specified time-points throughout the studies by quantitative PCR (qPCR) targeting the species specific $18 \mathrm{~S}$ ribosomal ribonucleic (rRNA) gene [48]. The studies involved evaluation of 18 different investigational antimalarial drugs, either alone or in combination (Additional file 1: Table S1). The day on which antimalarial treatment was administered ranged from day 7 to 8 for Pf3D7, day 9 for PfK13 and day 8 to 14 for P. vivax. For many of the studies, a sub-curative dose of the investigational drug was administered, resulting in recrudescence of parasitaemia to facilitate calculation of the drug minimum inhibitory concentrations. In all studies, participants were treated with a registered anti-malarial drug, typically artemetherlumefantrine, either at the time of recrudescence, or at the end of the study if recrudescence did not occur.

All studies were conducted in accordance with the Declaration of Helsinki and the International Committee of Harmonization Good Clinical Practice guidelines. Ethical approval for all studies was granted by the Human Research Ethics Committee at QIMR Berghofer. All participants provided informed written consent.

\section{Haematology measurements}

Blood was taken for standard haematology laboratory testing during screening, prior to inoculation, prior to antimalarial treatment, and then at protocol defined time-points throughout the study. The maximum volume of blood taken within a 30-day period was $400 \mathrm{~mL}$. For the purposes of analysis, baseline haemoglobin was defined as the last value prior to inoculation. Nadir haemoglobin was defined as the lowest haemoglobin from 
the day of first antimalarial treatment (termed 'day of treatment') onwards. The fractional fall in haemoglobin was the difference between baseline and nadir haemoglobin as a percentage of the baseline haemoglobin. The day of haemoglobin normalization was defined as the earliest day post-treatment at which the haemoglobin was equal to or greater than the baseline haemoglobin. The reticulocyte difference was defined as the difference between the baseline reticulocyte count prior to inoculation (day1 ) and the final reticulocyte count at the end of study.

\section{Statistical analysis}

Data was analysed using Stata V.16.0 and GraphPad Prism V.8.1. For categorical variables the number and frequency (\%) were reported, and differences between groups compared using Pearson Chi-squared test or Fisher's exact test. For normally distributed continuous variables the mean and standard deviation (SD) were reported and differences between groups were compared using the Student's t-test or analysis of variance (ANOVA). Nonnormally distributed continuous variables were summarized using the median and interquartile range (IQR) and differences between groups were compared using the Mann-Whitney and Kruskal-Wallis tests. The Wilcoxon signed-rank test was used to compare haemoglobin at baseline with haemoglobin at later time-points. In participants inoculated with $P$. vivax, the differences in haemoglobin parameters between those treated with artemether/lumefantrine and those treated with other drugs were compared using the non-parametric Dunn's multiple comparison test. Correlations between parasitaemia and haematological parameters were evaluated using either Pearson's or Spearman's correlation, depending on distribution.

Parasitaemia parameters evaluated included the $\log _{10}$ transformed pre-treatment peak parasitaemia $\left(\mathrm{PP}_{\mathrm{Pre}}\right)$, peak parasitaemia (PP; the highest parasitaemia within $24 \mathrm{~h}$ of treatment), and the pre-treatment total parasite burden $\left(\mathrm{TPB}_{\text {Pre }}\right)$. The $\mathrm{TPB}_{\text {Pre }}$ was determined using the area under curve (AUC) of the non-transformed 18S qPCR data from day 4 until the time of treatment. For $P$. falciparum, the $\mathrm{TPB}_{\text {Pre }}$ incorporated an adjustment to account for sequestered parasites, assumed to be approximately $25 \%$ of the total parasite burden at any given timepoint [49]. Linear regression analysis was used to evaluate the association between $\mathrm{TPB}_{\mathrm{Pre}}$ or $\mathrm{PP}_{\mathrm{Pre}}$ and the haematology parameters, adjusting for day of treatment and/or drug treatment. The parasite multiplication rates (PMR) and parasite reduction rates (PRR) were calculated as previously described $[50,51]$. Parasite recrudescence was defined as a parasitaemia increase by $>1000$ parasites $/ \mathrm{mL}$ occurring more than 2 days post-treatment.
For each participant, the total erythrocyte loss was calculated by subtracting the red cell count (RCC) at the day of haemoglobin nadir from the baseline RCC. The malaria-attributable loss was then calculated by subtracting the estimated phlebotomy-related erythrocyte loss from the total erythrocyte loss. For this calculation, the individual total blood volume was calculated using Nadler's method [52], with the phlebotomy-related erythrocyte loss estimated by multiplying the participant's baseline RCC $\left(\times 10^{12} / \mathrm{L}\right)$ by the estimated total phlebotomy blood volume from inoculation until the median day of haemoglobin nadir (total $0.19 \mathrm{~L} /$ total blood volume). To calculate the loss of parasitized RBCs as a proportion of the malaria-attributable erythrocyte loss, the $\mathrm{TPB}_{\mathrm{Pre}}$ (parasites per $\mathrm{mL}$ ) was divided by the malaria-attributable erythrocyte loss (see Additional file 1 for calculations). This calculation assumes that every parasitized erythrocyte is singly infected [53] and, therefore, the $\mathrm{TPB}_{\text {Pre }}$ is equal to the number of parasitized erythrocytes lost. The use of $\mathrm{TPB}_{\mathrm{Pre}}$ also assumes that parasite replication does not continue after treatment.

\section{Results}

\section{Participant's demographics}

The median ages of participants inoculated with Pf3D7 $(\mathrm{n}=254)$, PfK13 $(\mathrm{n}=15)$ and P. vivax $(\mathrm{n}=46)$ were 24 (IQR 22-28), 23 (IQR 21-27) and 24 (IQR 21-31) years, respectively. The majority of participants in all three groups were male (73\% in Pf3D7, 60\% in PfK13 and 65\% in $P$. vivax).

\section{Parasitaemia}

The overall median $\mathrm{PP}_{\mathrm{Pre}}$ for participants inoculated with P. falciparum was 10,277 (IQR 3566-27,815) parasites/ $\mathrm{mL}$ (Table 1). This was higher in participants inoculated with PfK13 (71,427 [IQR 33,236-180,218] parasites/ $\mathrm{mL})$ compared to Pf3D7 (9,008 [IQR 3341-21,798] parasites/mL; $\mathrm{p}<0.0001$ ), possibly due to the PfK13 participants being treated later (day 9) than those inoculated with Pf3D7 (day 7 or 8). The median PP in the P. falciparum group was 20,218 (IQR 8350-55,570) parasites/ $\mathrm{mL}$, which was again higher in the PfK13 group $(132,160$ [IQR 69,160-309,057 parasites/mL]) compared to the 3D7 group (18,240 [IQR 7,901-49,995] parasites/ml; $\mathrm{p}<0.0001)$. For participants inoculated with $P$. vivax the median PP $_{\text {Pre }}$ was 34,840 (IQR 13,302-77,064) parasites/ $\mathrm{mL}$, and the PP 53,696 (IQR 15,934-102,635) parasites/ $\mathrm{mL}$, with both these values being significantly higher than those inoculated with P. falciparum ( $<<0.001$ for both comparisons). Recrudescence occurred in 96/269 (36\%) participants in the P. falciparum group (15/15 [100\%] in PfK13 and 84/254 [33\%] in Pf 3D7), and 7/46 $(15 \%)$ in the $P$. vivax group. 
Table 1 Summary of haematology and parasite data

\begin{tabular}{|c|c|c|c|c|c|c|}
\hline & Pf all $(n=269)$ & Pf 3D7 $(n=254)$ & Pf K13 $(n=15)$ & P. vivax $(\mathrm{n}=46)$ & $\begin{array}{l}\text { P-value } \\
\text { (3D7 vs K13) }\end{array}$ & $\begin{array}{l}\text { P-value } \\
\text { (Pf all vs } \\
\text { P. vivax) }\end{array}$ \\
\hline Age, Years (Median, IQR) & $\begin{array}{l}24 \\
(22-28)\end{array}$ & $\begin{array}{l}24 \\
(22-28)\end{array}$ & $\begin{array}{l}23 \\
(21-27)\end{array}$ & $\begin{array}{l}24 \\
(21-31)\end{array}$ & 0.38 & 0.87 \\
\hline Male Sex, n (\%) & $197(73)$ & $188(74)$ & $9(60)$ & $30(65)$ & 0.23 & 0.26 \\
\hline $\mathrm{PP}_{\text {Pre' }}$ Parasites/mL (Median, IQR) & $\begin{array}{l}10,277 \\
(3566-27,815)\end{array}$ & $\begin{array}{l}9,008 \\
(3341-21,798)\end{array}$ & $\begin{array}{l}71,427 \\
(33,327-180,218)\end{array}$ & $\begin{array}{l}34,840 \\
(13,302-77,064)\end{array}$ & $<0.0001$ & $<0.0001$ \\
\hline PP, Parasites/mL (Median, IQR) & $\begin{array}{l}20,218 \\
(8350-55,570)\end{array}$ & $\begin{array}{l}18,240 \\
(7901-49,995)\end{array}$ & $\begin{array}{l}132,160 \\
(69,160-309,057)\end{array}$ & $\begin{array}{l}53,696 \\
(15,934-102,635)\end{array}$ & $<0.0001$ & 0.0006 \\
\hline $\mathrm{TPB}_{\text {Pre' }}$ Parasites/mL (Median, IQR) & $\begin{array}{l}30,223^{\mathrm{a}} \\
(14,320-90,970)\end{array}$ & $\begin{array}{l}28,366^{\mathrm{a}} \\
(12,637-75,571)\end{array}$ & $\begin{array}{l}410,274^{\mathrm{a}} \\
(166,853-1,106,184)\end{array}$ & $\begin{array}{l}31,345 \\
(12,264-67,516)\end{array}$ & $<0.0001$ & 0.38 \\
\hline PRR (Median, IQR) & $\begin{array}{l}0.058 \\
(0.045-0.081)\end{array}$ & $\begin{array}{l}0.060 \\
(0.045-0.082)\end{array}$ & $\begin{array}{l}0.051 \\
(0.045-0.055)\end{array}$ & $\begin{array}{l}0.055 \\
(0.048-0.068)\end{array}$ & 0.040 & 0.37 \\
\hline Baseline Hb, g/L (Median, IQR) & $\begin{array}{l}149 \\
(139-156)\end{array}$ & $\begin{array}{l}149 \\
(141-156)\end{array}$ & $\begin{array}{l}145 \\
(136-153)\end{array}$ & $\begin{array}{l}147 \\
(139-158)\end{array}$ & 0.27 & 0.74 \\
\hline Day of Treatment Hb, g/L (Mean, SD) & $\begin{array}{l}139 \\
(12.09)\end{array}$ & $\begin{array}{l}140 \\
(11.81)\end{array}$ & $\begin{array}{l}136 \\
(16.11)\end{array}$ & $\begin{array}{l}140 \\
(12.61)\end{array}$ & 0.22 & 0.57 \\
\hline Nadir Hb, g/L (Median, IQR) & $\begin{array}{l}132 \\
(123-140)\end{array}$ & $\begin{array}{l}132 \\
(123-140)\end{array}$ & $\begin{array}{l}127 \\
(110-135)\end{array}$ & $\begin{array}{l}129 \\
(121-140)\end{array}$ & 0.024 & 0.22 \\
\hline Hb Fractional Fall, \% (Median, IQR) & $\begin{array}{l}10.6 \\
(7.9-13.8)\end{array}$ & $\begin{array}{l}10.3 \\
(7.8-13.3)\end{array}$ & $\begin{array}{l}14.8 \\
(11.8-15.9)\end{array}$ & $\begin{array}{l}11.7 \\
(8.9-14.5)\end{array}$ & 0.001 & 0.07 \\
\hline Day Post Treatment of Hb Nadir (Median, IQR) & $\begin{array}{l}12 \\
(5-21)\end{array}$ & $\begin{array}{l}12 \\
(5-21)\end{array}$ & $\begin{array}{l}15 \\
(7-22)\end{array}$ & $\begin{array}{l}8 \\
(7-15)\end{array}$ & 0.66 & 0.11 \\
\hline $\begin{array}{l}\text { Day Post Treatment of return to baseline } \mathrm{Hb} \\
\text { (Median, IQR) }\end{array}$ & $\begin{array}{l}28^{b} \\
(22-37)\end{array}$ & $\begin{array}{l}28^{\mathrm{b}} \\
(22-37)\end{array}$ & c & $\begin{array}{l}20 \\
(18-25)\end{array}$ & c & $<0.0001$ \\
\hline $\begin{array}{l}\% \text { Contribution of pre-treatment } \mathrm{Hb} \text { drop to } \\
\text { total drop in } \mathrm{Hb} \text { (Median, IQR) }\end{array}$ & $\begin{array}{l}55 \\
(23-78)\end{array}$ & $\begin{array}{l}55 \\
(24-78)\end{array}$ & $\begin{array}{l}40 \\
(11-76)\end{array}$ & $\begin{array}{l}45 \\
(27-56)\end{array}$ & 0.45 & 0.020 \\
\hline $\begin{array}{l}\text { Baseline reticulocyte count, } 10^{9} / \mathrm{L} \text { (Median, } \\
\text { IQR) }\end{array}$ & $\begin{array}{l}55^{d} \\
(44-68)\end{array}$ & $\begin{array}{l}54^{d} \\
(43-68)\end{array}$ & $\begin{array}{l}58 \\
(49-76)\end{array}$ & $\begin{array}{l}58 \\
(46-74)\end{array}$ & 0.33 & 0.34 \\
\hline $\begin{array}{l}\text { Maximum post-treatment reticulocyte count, } \\
10^{9} / \mathrm{L} \text { (Median, IQR) }\end{array}$ & $\begin{array}{l}68^{d} \\
(54-90)\end{array}$ & $\begin{array}{l}66^{d} \\
(53-89)\end{array}$ & $\begin{array}{l}84 \\
(66-100)\end{array}$ & $\begin{array}{l}72^{\mathrm{e}} \\
(58-89)\end{array}$ & 0.048 & 0.29 \\
\hline Reticulocyte difference, $10^{9} / \mathrm{L}$ (Median, IQR) & $\begin{array}{l}12^{f} \\
(3-28)\end{array}$ & $\begin{array}{l}11^{9} \\
(1-27)\end{array}$ & $\begin{array}{l}20 \\
(10-33)\end{array}$ & $\begin{array}{l}13^{\mathrm{e}} \\
(4-23)\end{array}$ & 0.049 & 0.99 \\
\hline
\end{tabular}

n-number of participants; IQR- interquartile range; PP- peak parasitaemia; $\mathrm{PP}_{\text {Pre }}$ - pre-treatment peak parasitaemia; $\mathrm{TPB}_{\text {Pre }}$ - pre-treatment total parasite burden, determined using the AUC of the $18 \mathrm{~S}$ qPCR data from day 4 until the time of treatment; PRR-parasite reduction ratio

${ }^{a}$ The TPB $B_{\text {Pre }}$ for the $P$. falciparum groups has been adjusted by a factor of $25 \%$ to account for sequestered parasites [50]; ${ }^{b} P f$ all $n=267$ and $P f 3 D 7 n=252$ due to 2 participants not reaching haemoglobin baseline; ${ }^{C}$ none of the PfK13 participants' haemoglobin returned to baseline; ${ }^{d} P f$ all $n=254$ and Pf3D7 $n=239$; ${ }^{e}=44$; $\mathrm{f}=246 ;{ }^{9} \mathrm{n}=231$; Mann-Whitney test used unless otherwise stated

\section{Fall in haemoglobin following inoculation with $P$. falciparum and $P$. vivax}

In all participants inoculated with $P$. falciparum, the median haemoglobin fell from a baseline of 149 (IQR 139-156) g/L to a nadir of 132 (IQR 123-140) g/L, representing a median fall of $17 \mathrm{~g} / \mathrm{L}$ and a fractional fall of $10.6 \%$ (IQR 7.9-13.8\%) (Table 1). The fall in haemoglobin prior to anti-malarial treatment accounted for a median $55 \%$ (IQR 23-78\%) of the total fall. The haemoglobin nadir occurred a median of 12 (IQR 5-21) days post treatment and returned to baseline a median of 28 (IQR 22-37) days post treatment.

There was no significant difference between the median baseline haemoglobin between participants inoculated with Pf3D7 (149 g/L [IQR 141-156]) and those inoculated with PfK13 (145 g/L [IQR 136-153]; $\mathrm{p}=0.27)$. In participants with PfK13, the haemoglobin fell by a median 18 (IQR 12-23) g/L compared to 17 (IQR 11-20) $\mathrm{g} / \mathrm{L}$ in the Pf3D7 group, representing a median fractional fall of $14.8 \%$ (IQR $11.8-15.9 \%$ ), compared to $10.3 \%$ (IQR $7.8-13.3 \%$ ) in the $3 \mathrm{D} 7$ group $(\mathrm{p}=0.001)$ (Fig. 1). The day of haemoglobin nadir occurred a median of 15 (IQR 7-22) days post treatment in those inoculated with PfK13 compared 12 (IQR $5-21)$ days in those inoculated with Pf3D7 ( $p=0.66)$. In participants inoculated with the Pf3D7, the haemoglobin returned to baseline a median 28 (IQR 22-37) days post-treatment, while in the PfK13 group, the 

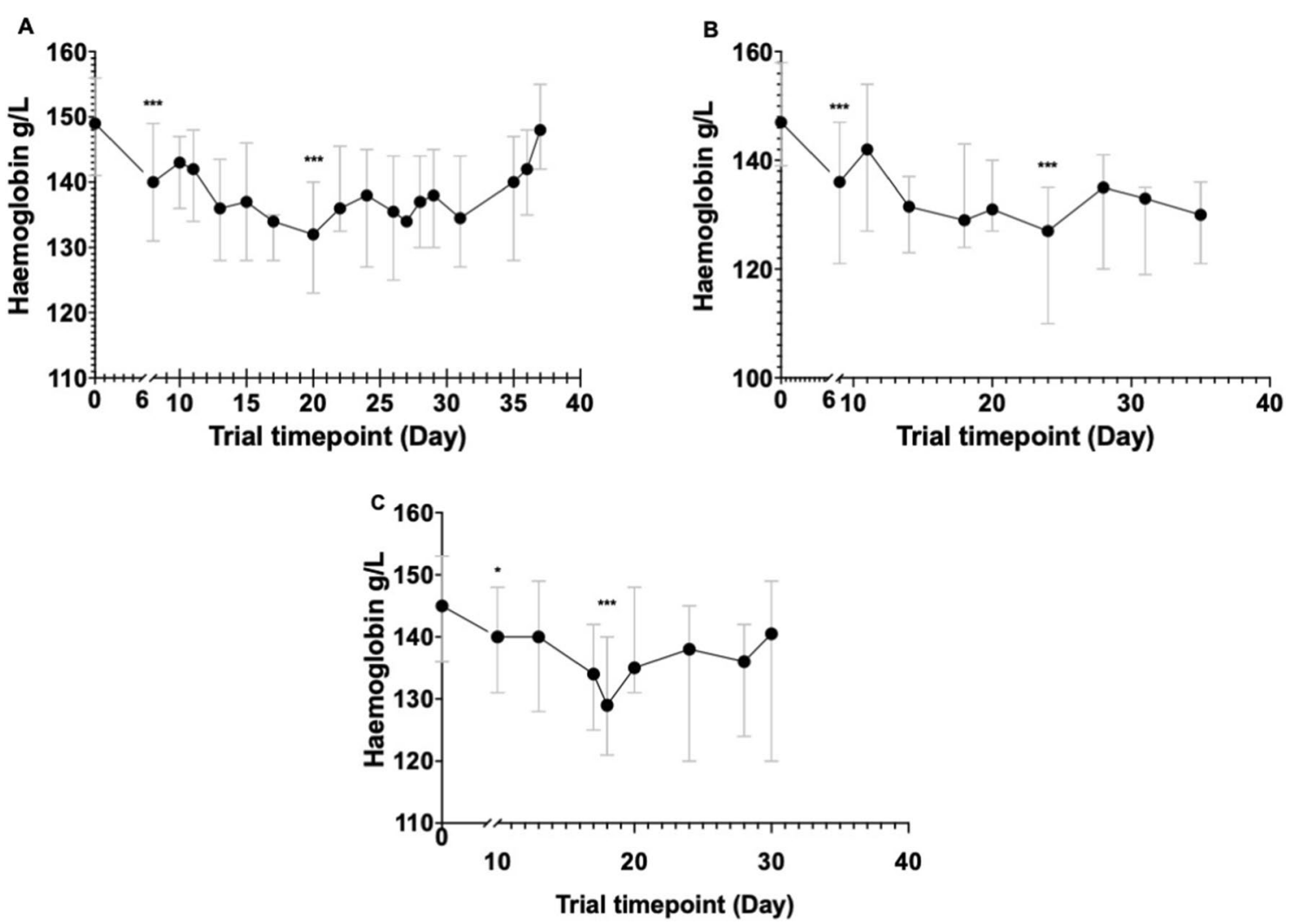

Fig. 1 Changes in haemoglobin over time in participants inoculated with Pf3D7 (A), PfK13 (B) and P. vivax (C). Data points and error bars represent median and interquartile range, respectively. Values were compared to the values at baseline using the Wilcoxon matched-paired sign-rank test. *indicates a $p$ value of 0.037 , and ${ }^{* * *}$ indicates a $p$ value of $<0.001$, for comparisons with baseline haemoglobin

haemoglobin did not recover to baseline levels prior to the end of study in any of the 15 participants (Table 1).

In participants inoculated with $P$. vivax, the haemoglobin fell from a median of 147 (IQR 139-158) g/L to 129 (IQR 121-140) g/L, with a total median fall of 18 (IQR $14-21$ ) $\mathrm{g} / \mathrm{L}$ and a median fractional fall of $11.7 \%$ (IQR 8.9-14.5), which compared to $10.6 \%$ (IQR 7.9-13.8) in the $P$. falciparum group $(\mathrm{p}=0.07)$. The median fall in haemoglobin prior to treatment contributed to $45 \%$ (IQR 27-56) of the total fall. The haemoglobin nadir occurred a median of 8 (IQR 7-15) days following treatment and returned to baseline levels a median of 20 (IQR 18-25) days following treatment.

\section{Factors influencing fall in haemoglobin \\ Recrudescence}

In participants inoculated with P. falciparum, 99 (37\%) participants who recrudesced had a fractional fall in haemoglobin of $12.0 \%$ (IQR 8.1-15.2; $\mathrm{n}=99$ ), compared to $10.2 \%$ (IQR $7.7-12.8 ; \mathrm{n}=170$ ) in those who did not $(\mathrm{p}=0.006)$. In the $P$. vivax group, the median haemoglobin fractional fall was similar in those who recrudesced
(11.8\% [IQR 8.7-16.4]; $\mathrm{n}=7$ ) compared to those who did $\operatorname{not}(11.7 \%$ [IQR $8.8-14.5 ; \mathrm{n}=39] ; \mathrm{p}=0.95)$.

\section{Age, sex and day of treatment}

In the P. falciparum participants, there was no significant difference observed in the haemoglobin nadir or fractional fall in haemoglobin between age groups (Additional file 1: Table S4). In participants inoculated with $P$. vivax, a trend was observed towards a greater fractional fall of haemoglobin in the older age group (median 13.6\% [IQR 10.8-14.6; $\mathrm{n}=21$ ] vs $10.5 \%$ [IQR 8.5-14.0; $\mathrm{n}=25$ ]; $\mathrm{p}=0.09$ ) (Additional file 1: Table S5), although this was not statistically significant.

Gender had no effect on the fractional fall in haemoglobin across all three species. Females had a lower median baseline haemoglobin than males $(134 \mathrm{~g} / \mathrm{L}$ [IQR $127-138 ; \mathrm{n}=88$ ] vs $153 \mathrm{~g} / \mathrm{L}$ [IQR $147-158 ; \mathrm{n}=227$ ]; $\mathrm{N}=315 ; \mathrm{p}<0.0001)$ as well as a lower haemoglobin nadir (117 g/L [IQR 111-123; $\mathrm{n}=88$ ] vs $136 \mathrm{~g} / \mathrm{L}$ [IQR 130-142; $\mathrm{n}=227$ ]; $\mathrm{N}=315 ; \mathrm{p}<0.0001)$.

In participants inoculated with Pf3D7, the day of treatment did not have any significant impact on the 
haematology parameters (Additional file 1: Table S6). However, for participants inoculated with $P$. vivax, where day of treatment was more variable, the median haemoglobin nadir was lower in participants treated on Day 10-14 (129 g/L [120-137]; $\mathrm{n}=36)$, compared to those treated on Day 8 (140 g/L [133-144]; $\mathrm{n}=10 ; \mathrm{p}=0.049)$. The median fractional fall in haemoglobin was also greater in those treated at Day 10-14 (12.4\% [IQR 9.714.6]), compared to those treated on Day 8 (8.8\% [IQR 7.2-11.7]; $\mathrm{p}=0.030$ ) (Additional file 1: Table S7). All participants in the PfK13 were treated on Day 9.

\section{Drugs}

There were sixteen single or combination drugs assessed in the Pf3D7 participants (Table 2). However, substantial heterogeneity existed among these studies, precluding statistical analysis of drug effect on the fractional fall in haemoglobin. In particular, treatment was administered on day 7 in 10 studies, and on day 8 in 10 studies. The end of study (EOS) also varied, from Day 36 in the
ZY-19489 study to Day 50 in the M5717 study. Recrudescence occurred more frequently in the ACT-451840 (7/8 participants) and SJ733 (6/16 participants) studies compared to the ferroquine study where no individuals recrudesced. Although statistical analysis was not performed, fractional falls in haemoglobin were numerically lowest in those treated with griseofulvin (8.5\% [IQR 6.89.3; $\mathrm{n}=3]$ ), and highest in those treated with MMV048 (11.4\% [IQR 8.4-14.2; $\mathrm{n}=13$ ) (Fig. 2).

Participants inoculated with $P$. vivax were treated with either chloroquine $(n=24)$, artefenomel $(n=8)$ or artemether/lumefantrine $(\mathrm{n}=14)$, with no significant differences in the haemoglobin parameters observed between treatment groups (Additional file 1: Table S8). The PfK13 participants were all administered artesunate as the investigational medical product.

There was no correlation between speed of parasite killing (PRR) and fractional fall of haemoglobin in the overall $P$. falciparum and $P$. vivax groups (Additional file 1: Table S9). There was however a strong inverse

Table 2 Haemoglobin parameters in participants inoculated with Pf 3D7 who did not recrudesce, according to drug treatment

\begin{tabular}{|c|c|c|c|}
\hline $\begin{array}{l}\text { Pf3D7 }(n=168) \\
\text { Drugs }(n)\end{array}$ & $\begin{array}{l}\text { Nadir, g/L } \\
\text { (median, IQR) }\end{array}$ & $\begin{array}{l}\text { Fractional Fall } \\
(\%, \text { median, IQR) }\end{array}$ & $\begin{array}{l}\text { Day post } \\
\text { treatment of } \mathrm{Hb} \\
\text { Nadir } \\
\text { (median, IQR) }\end{array}$ \\
\hline ACT-451840 (1) & 136 & 9.33 & 9 \\
\hline DSM265 (12) & $\begin{array}{l}135 \\
(130-141)\end{array}$ & $\begin{array}{l}10.9 \\
(10.4-12.9)\end{array}$ & $\begin{array}{l}21 \\
(14-23)\end{array}$ \\
\hline DSM265 + Artefenomel (7) & $\begin{array}{l}115 \\
(114-139)\end{array}$ & $\begin{array}{l}10.6 \\
(6.1-11.6)\end{array}$ & $\begin{array}{l}21 \\
(20-28)\end{array}$ \\
\hline Ferroquine (8) & $\begin{array}{l}129 \\
(118-133)\end{array}$ & $\begin{array}{l}11.3 \\
(9.3-12.8)\end{array}$ & $\begin{array}{l}20 \\
(18-21)\end{array}$ \\
\hline Griseofulvin (3) & $\begin{array}{l}140 \\
(136-146)\end{array}$ & $\begin{array}{l}8.5 \\
(6.8-9.3)\end{array}$ & $\begin{array}{l}11 \\
(4-20)\end{array}$ \\
\hline Cipargamin (4) & $\begin{array}{l}139 \\
(133-144)\end{array}$ & $\begin{array}{l}10.0 \\
(8.0-13.0)\end{array}$ & $\begin{array}{l}20 \\
(12-23)\end{array}$ \\
\hline M5717 (20) & $\begin{array}{l}136 \\
(132-142)\end{array}$ & $\begin{array}{l}10.6 \\
(8.5-12.9)\end{array}$ & $\begin{array}{l}10 \\
(6-14)\end{array}$ \\
\hline MMV048 (13) & $\begin{array}{l}138 \\
(131-143)\end{array}$ & $\begin{array}{l}11.4 \\
(8.4-14.2)\end{array}$ & $\begin{array}{l}9 \\
(8-12)\end{array}$ \\
\hline Mefloquine (22) & $\begin{array}{l}127 \\
(120-139)\end{array}$ & $\begin{array}{l}9.1 \\
(7.9-14.7)\end{array}$ & $\begin{array}{l}4 \\
(0-9)\end{array}$ \\
\hline Artefenomel (16) & $\begin{array}{l}125 \\
(119-139)\end{array}$ & $\begin{array}{l}8.6 \\
(7.5-9.7)\end{array}$ & $\begin{array}{l}8 \\
(1-21)\end{array}$ \\
\hline Artefenomel + Piperaquine (21) & $\begin{array}{l}132 \\
(127-140)\end{array}$ & $\begin{array}{l}9.1 \\
(7.0-13.2)\end{array}$ & $\begin{array}{l}14 \\
(0-27)\end{array}$ \\
\hline Piperaquine (23) & $\begin{array}{l}129 \\
(120-140)\end{array}$ & $\begin{array}{l}10.8 \\
(6.3-13.0)\end{array}$ & $\begin{array}{l}19 \\
(0-23)\end{array}$ \\
\hline Piperaquine + Primaquine (2) & $127-138$ & $4.2-13.0$ & $7-20$ \\
\hline SJ733 (10) & $\begin{array}{l}136 \\
(130-140)\end{array}$ & $\begin{array}{l}9.8 \\
(8.3-11.6)\end{array}$ & $\begin{array}{l}12 \\
(10-20)\end{array}$ \\
\hline ZY-19849 (6) & $\begin{array}{l}128 \\
(122-137)\end{array}$ & $\begin{array}{l}10.9 \\
(5.5-11.6)\end{array}$ & $\begin{array}{l}7 \\
(3-8)\end{array}$ \\
\hline
\end{tabular}




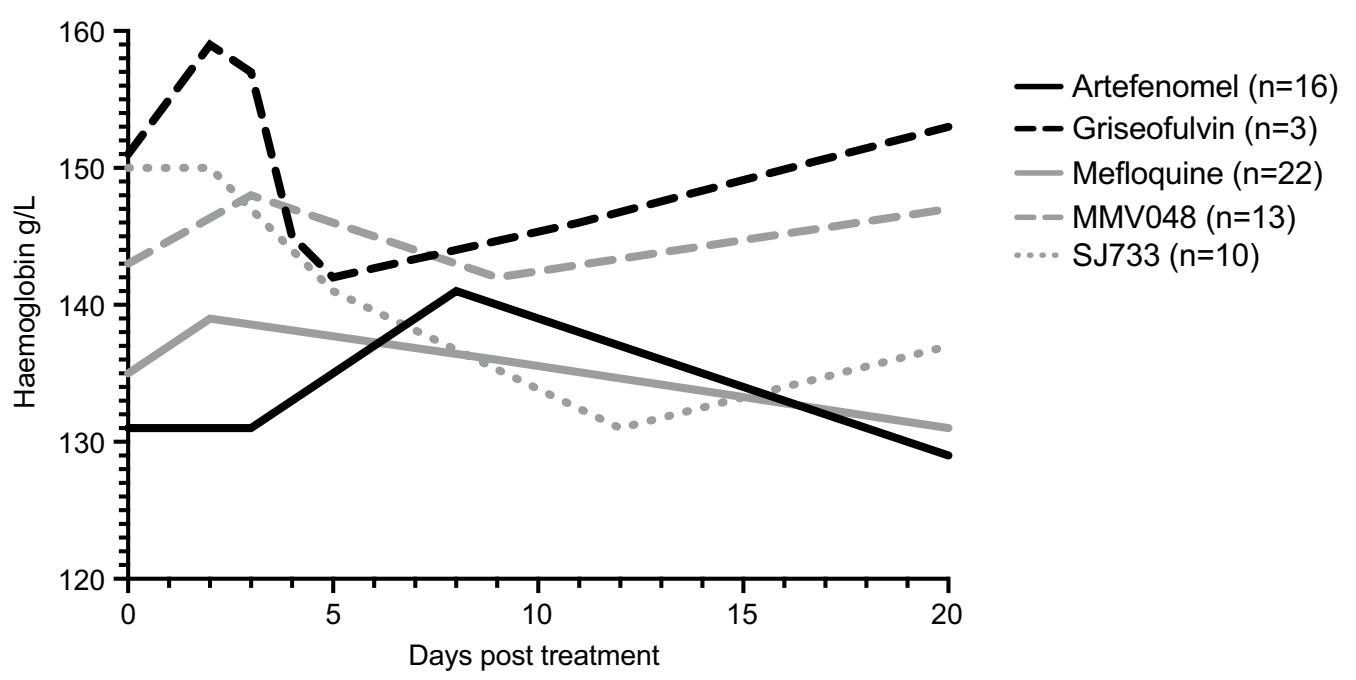

Fig. 2 Median haemoglobin in participants inoculated with Pf3D7 who did not recrudesce, according to drug treatment

correlation between PRR $(\mathrm{r}=-0.57, \mathrm{p}=0.026)$ and the fractional fall in haemoglobin in the PfK13 group (Additional file 1: Table S10).

\section{Effect of parasitaemia}

In those inoculated with Pf3D7 and who did not experience recrudesce $(n=170)$, there were no correlations between any of the parasitaemia variables and haemoglobin nadir or fractional fall in haemoglobin, even after adjusting for drugs (Table 3 ). There were however strong correlations between $\mathrm{PP}_{\text {Pre }}(\mathrm{r}=0.66, \mathrm{p}=0.007)$ and PMR $(\mathrm{r}=0.61, \mathrm{p}=0.016)$ and the fractional fall in haemoglobin in the PfK13 group, although all (15/15) PfK13 participants recrudesced (Additional file 1: Table S10).

In participants inoculated with $P$. vivax and who did not experience recrudescence $(\mathrm{n}=39)$, the $\mathrm{PP}_{\text {Pre }}$ correlated with the fractional fall in haemoglobin $(r=0.32$, $\mathrm{p}=0.045)$, with this correlation remaining significant when adjusted for drugs $(\mathrm{p}=0.041)$. The $\mathrm{TPB}_{\text {Pre }}$ correlated with the haemoglobin nadir $(\mathrm{r}=-0.57, \mathrm{p}=0.0001)$ and fractional fall in haemoglobin $(r=0.39, p=0.013)$, with both correlations remaining significant after adjustment for drug $(\mathrm{p}=0.0001$ and $\mathrm{p}=0.040$, respectively) (Table 3).

\section{Malaria-attributable erythrocyte loss and the contribution of parasitized erythrocytes to the malaria-attributable erythrocyte loss}

In participants inoculated with $P$. falciparum, the median total erythrocyte loss from inoculation until the day of haemoglobin nadir was 0.5 (IQR $0.3-0.7) \times 10^{12}$ erythrocytes/L, with this loss being greater in those inoculated with PfK13 (median 0.7 [IQR 0.6-0.8] $\times 10^{12} / \mathrm{L}$ ) compared to Pf3D7 (median 0.5 [IQR $0.3-0.6] \times 10^{12} / \mathrm{L}$; $\mathrm{p}=0.0005$ ) (Table 4). The erythrocyte loss in those inoculated with $P$. vivax (median 0.5 [IQR $0.4-0.6] \times 10^{12}$

Table 3 Correlations between parasite parameters and haemoglobin variables in P. falciparum and P. vivax in those who did not recrudesce

\begin{tabular}{|c|c|c|c|c|c|c|}
\hline \multirow[t]{2}{*}{ Correlation } & \multicolumn{3}{|c|}{ Pf3D7 $(n=170)$} & \multicolumn{3}{|c|}{ P. vivax $(\mathrm{n}=39)$} \\
\hline & r-value & $\begin{array}{l}\text { Unadjusted } \\
\text { P-value }^{a^{a}}\end{array}$ & $\begin{array}{l}\text { Adjusted } \\
\text { P-value }^{\mathrm{b}}\end{array}$ & r-value & $\begin{array}{l}\text { Unadjusted } \\
\text { P-value }^{\mathrm{a}}\end{array}$ & $\begin{array}{l}\text { Adjusted } \\
\text { P-value }^{c}\end{array}$ \\
\hline $\mathrm{PP}_{\text {Pre }}$ and Haemoglobin nadir & 0.06 & 0.44 & 0.82 & -0.47 & 0.002 & 0.001 \\
\hline $\mathrm{PP}_{\text {Pre }}$ and Fractional Fall of Haemoglobin & -0.05 & 0.49 & 0.43 & 0.32 & 0.045 & 0.041 \\
\hline $\mathrm{TPB}_{\text {Pre }}$ and Haemoglobin nadir & 0.07 & 0.39 & 0.99 & -0.57 & 0.0001 & 0.002 \\
\hline $\mathrm{TPB}_{\text {Pre }}$ and Fractional Fall of Haemoglobin & -0.01 & 0.89 & 0.78 & 0.39 & 0.013 & 0.040 \\
\hline
\end{tabular}

$n$ number of participants, $T P B_{\text {Pre }}$ pre-treatment total parasite burden, $P P_{\text {Pre }}$ Pre-treatment peak parasitaemia

${ }^{\text {a }}$ Pearson's correlation (with $\mathrm{PP}_{\mathrm{Pre}}$ and TBP $\log _{10}$ transformed); ${ }^{\mathrm{b}}$ adjusted for drugs by including drug as an explanatory variable in a linear regression model; ${ }^{c}$ adjusted for drugs and by day of treatment by including drug and day of treatment as explanatory variables in a linear regression model 


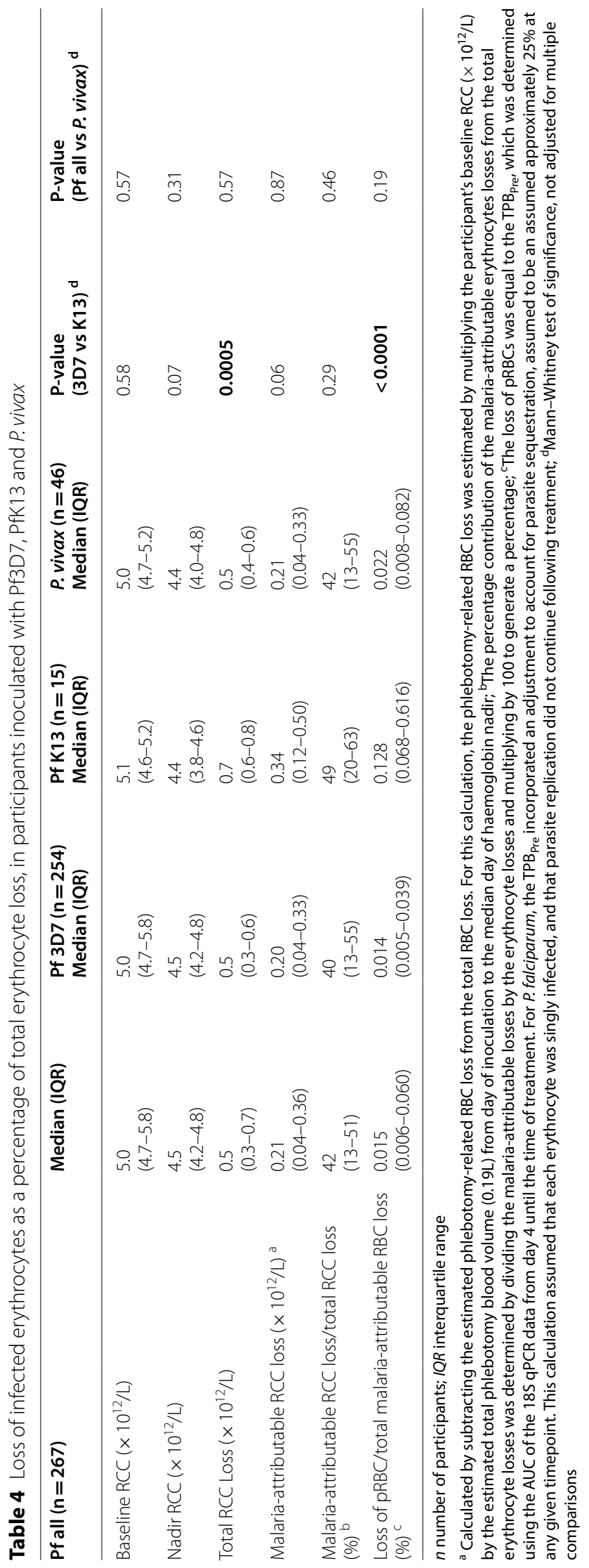


erythrocytes/L) was similar to those inoculated with Pf3D7.

The malaria-attributable erythrocyte loss was estimated to be a median 0.21 (IQR $0.04-0.36) \times 10^{12} / \mathrm{L}$ in participants inoculated with $P$. falciparum, or $\sim 42 \%$ of the total erythrocyte loss. Again, this loss was greater in the PfK13 group (median 0.34 [IQR 0.12-0.50] $\times 10^{12} / \mathrm{L}$, or $49 \%$ of the total erythrocyte loss) compared to Pf3D7 group (median 0.20 [IQR $0.04-0.33] \times 10^{12} / \mathrm{L}$, or $40 \%$ of the total erythrocyte loss). In the $P$. vivax group, the median malaria-attributable erythrocyte loss was 0.21 (IQR $0.4-0.33) \times 10^{12} / \mathrm{L}$, similar to the erythrocyte loss in the Pf3D7 group (Table 4). Applying these percentages to the fractional fall in haemoglobin, the malaria-attributable fractional fall in haemoglobin was 4.1\% (IQR 3.1-5.3) in those inoculated with Pf3D7 group, 7.2\% (IQR 5.8-7.8) in those inoculated with PfK13, and 4.9\% (IQR 3.7-6.1) in those inoculated with $P$. vivax.

In participants inoculated with $P$. falciparum, parasitized cells accounted for an estimated $0.015 \%$ (IQR $0.006-0.060 \%)$ of the malaria-attributable erythrocyte loss. This proportion was significantly higher in the PfK13 group (median 0.128 [IQR 0.068-0.616] \%) compared to the Pf3D7 group (0.014 [IQR 0.005$0.039] \%, \mathrm{p}<0.0001)$. In those inoculated with $P$. vivax, parasitized cells accounted for an estimated 0.022 (IQR $0.008-0.082) \%$ of the malaria-attributable erythrocyte loss. The loss of parasitized cells as a percentage of the total malaria-attributable erythrocyte loss was associated with the $\mathrm{TPB}_{\text {Pre }}$ in participants inoculated with each species ( $P$. falciparum $\mathrm{r}=0.83, \mathrm{p}<0.001 ; P$. vivax $\mathrm{r}=0.63, \mathrm{p}<0.001)$ and with each $P$. falciparum inocula (Pf3D7 $\mathrm{r}=0.81, \mathrm{p}<0.001$; PfK13 $\mathrm{r}=0.56, \mathrm{p}=0.035)$.

\section{Reticulocyte response}

In those inoculated with $P$. falciparum, the reticulocyte count increased from a median of 55 (IQR $44-68) \times 10^{9} / \mathrm{L}$ at baseline to 68 (IQR $\left.54-90\right) \times 10^{9} / \mathrm{L}$ at EOS, representing a median $22 \%$ increase $(\mathrm{p}=0.0001)$ (Table 1, Fig. 3). A similar increase was seen among those inoculated with $P$. vivax. There was a significant correlation between the reticulocyte response and total erythrocyte loss in the $P$. falciparum group $(\mathrm{r}=0.13$, $\mathrm{p}=0.04 ; \mathrm{n}=240$ ) but not in the in the $P$. vivax group $(\mathrm{r}=0.08, \mathrm{p}=0.60 ; \mathrm{n}=44)$. In the $P$. falciparum group, there was a correlation between age and the reticulocyte response $(\mathrm{r}=0.15, \mathrm{p}=0.019 ; \mathrm{n}=240)$, although this was not observed in the $P$. vivax group.

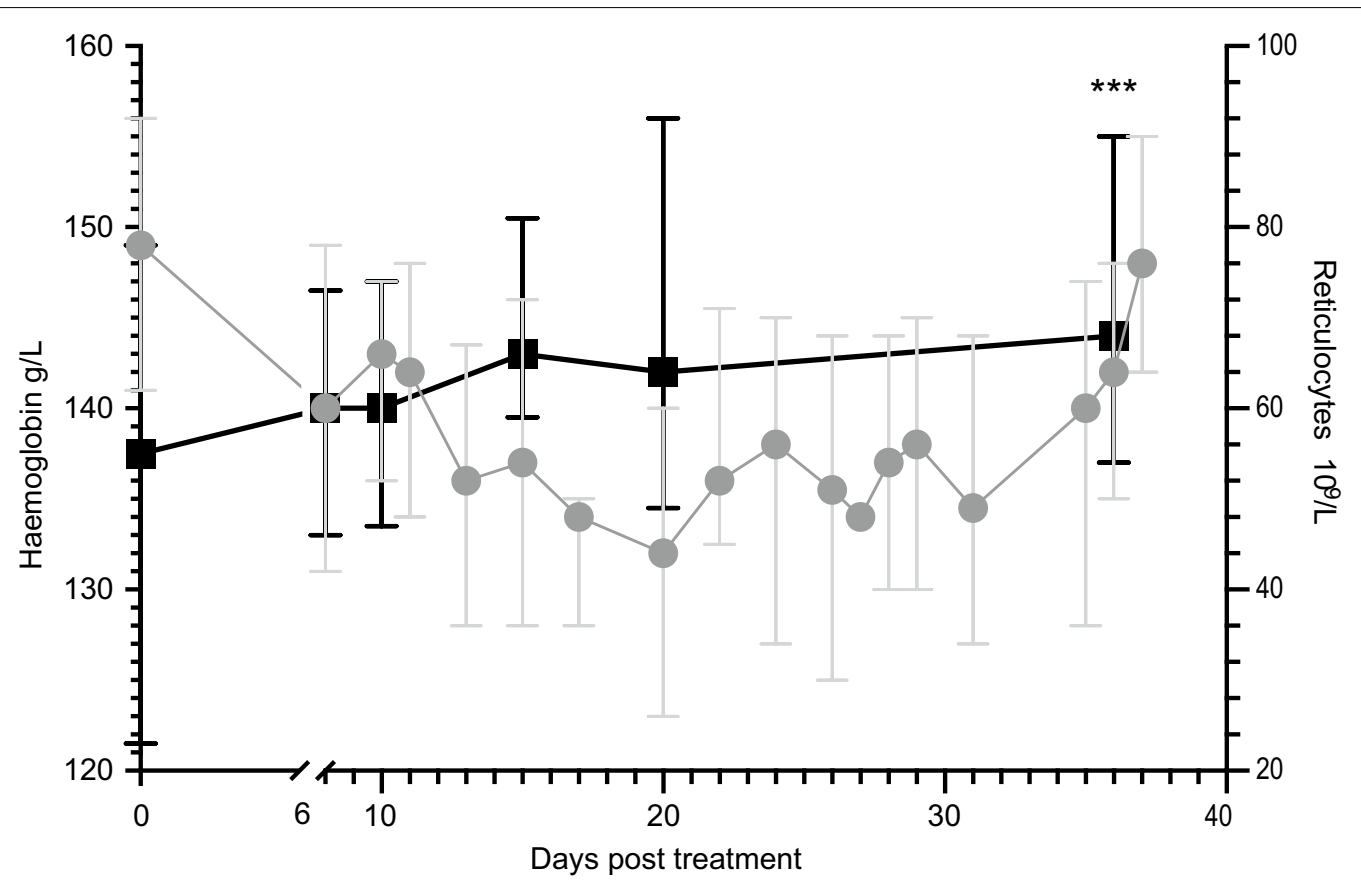

Haemoglobin

Reticulocytes

Fig. 3 Median haemoglobin and reticulocyte count over time in participants inoculated with Pf3D7 $(n=254)$. Error bars represent interquartile range. Values were compared to the values at baseline using the Wilcoxon matched-paired sign-rank test. *** $p<0.0001$ (for the difference between the reticulocyte count at end of study and the reticulocyte count at baseline) 


\section{Discussion}

In this study, the haematological response to early experimental $P$. falciparum and $P$. vivax infection is described. The analysis demonstrates that in both $P$. falciparum and $P$. vivax, experimental infection results in an $\sim 11 \%$ fractional fall in haemoglobin, approximately half of which occurs prior to treatment. The haemoglobin nadir occurred $\sim 12$ days after treatment in participants inoculated with $P$. falciparum and 8 days in participants inoculated with $P$. vivax, returning to normal by 28 days in $P$. falciparum and 20 days in $P$. vivax.

Volunteer infection studies are associated with frequent blood sampling, and it was estimated that phlebotomy-related losses accounted for $\sim 60 \%$ of the total fractional fall in haemoglobin. Nonetheless, the malariaattributable loss from early experimental malaria, with parasitaemias only just reaching the limit of detection by microscopy, still accounted for a fractional fall in haemoglobin of $\sim 4 \%$ in Pf3D7, 7\% in PfK13 and $~ 5 \%$ in $P$. vivax, after accounting for phlebotomy related losses. It should be noted that in experimental malaria the duration of parasitaemia prior to treatment is only a few days, in contrast to endemic regions where low-level asymptomatic parasitaemia may persist in partially immune individuals for prolonged periods, thus the haemoglobin loss may be expected to be substantially greater. This is supported by recent studies from endemic regions, which have demonstrated a significant burden of anaemia associated with submicroscopic parasitaemia $[10,11]$.

In participants inoculated with $P$. falciparum, the fractional fall in haemoglobin was greater in those inoculated with an artemisinin-resistant PfK13 strain, compared to those inoculated with the artemisinin-sensitive Pf3D7 strain. Contributing factors that may have accounted for this greater fractional fall include a later day of treatment and higher parasitaemias in participants inoculated with PfK13 compared to Pf3D7, as well as the slower parasite reduction ratio, and the recrudescence that occurred in all of the PfK13 participants following treatment with artesunate. The day of haemoglobin nadir also occurred later in the PfK13 participants, and no participant recovered their haemoglobin prior to the end of study, again likely reflecting delayed parasite clearance and recrudescent parasitaemia. In the PfK13 participants the parasite reduction ratio was significantly and inversely correlated with the fall in haemoglobin, with slower parasite clearance associated with greater haemoglobin fall. Although this study was not designed to directly compare haemoglobin losses in participants inoculated with PfK13 vs Pf3D7, the results reported here are consistent with data from clinical studies reporting a greater incidence of anaemia in patients with drug-resistant $P$. falciparum [54, $55]$ and those given drugs with slower parasite clearance effects [56-59]. Thus, while this study did not allow direct comparison of the effect of different drugs on haemoglobin loss, the impact of parasite clearance on rates of anaemia should be considered in clinical trials evaluating antimalarials.

Consistent with the greater fall in haemoglobin in participants inoculated with PfK13, all of whom recrudesced, within the Pf3D7 group those who recrudesced also experienced a significantly greater fall in haemoglobin. These data are consistent with previous studies which have also demonstrated higher rates of anaemia associated with parasite recrudescence $[13,60]$.

It is also possible that the greater fractional fall in haemoglobin observed in participants inoculated with PfK13 may have been due in part to the fact that these participants were treated with artesunate. Post-artesunate anaemia is well described, and results from delayed clearance of once-infected erythrocytes [23]. However, it is unlikely that this would be a significant contributor to erythrocyte loss at such low parasitaemias, and no participant inoculated with PfK13 had elevated markers of haemolysis [44].

In participants inoculated with $P$. vivax, we found that delaying day of treatment was associated with a greater fall in haemoglobin. This is also consistent with clinical studies reporting correlations between the time since symptom onset and degree of anaemia [61-64], and highlights the importance of early initiation of treatment.

In participants inoculated with $P$. vivax, a correlation between parasitaemia (whether measured as peak parasitaemia, or pre-treatment total parasite burden) and the fractional fall in haemoglobin was observed. This is as expected, and consistent with clinical data demonstrating a correlation between parasitaemia and anaemia [63, 64]. Unexpectedly, this association was not observed in the much larger group of participants inoculated with Pf3D7. It is possible the heterogeneity of the Pf3D7 studies (with different treatment days and different drugs evaluated), together with the low parasitaemias, may have obscured any association between parasitaemia and fractional fall in haemoglobin.

In this study we attempted to quantify the loss of parasitized cells as a proportion of the overall malariaattributable erythrocyte loss. Similar analyses have been conducted previously, including in clinical malaria in endemic regions [13], and in neurosyphilis patients receiving malariotherapy $[12,14]$. In the former study, Price et al. [13] evaluated the haematological response to $P$. falciparum malaria in over 4000 children and adults in Thailand during 1990-1995, and estimated that parasitized cells accounted for $7.9 \%$ of the total malariaattributable loss. A similar estimate was obtained by Jakeman et al. [12], who used data from neurosyphilis 
patients undergoing malariotherapy to estimate that $P$. falciparum parasitized cells accounted for $\sim 10.5 \%$ of erythrocytes lost. In neurosyphilis patients inoculated with $P$. vivax, Collins et al. [14] estimated that only $2.9 \%$ of the reduction in haemoglobin was due to destruction of parasitized erythrocytes. In the current study involving very low parasitaemias, our analyses demonstrated that parasitized cells accounted for only $0.015 \%$ of erythrocytes lost in volunteers inoculated with Pf3D7, and $0.022 \%$ in those inoculated with $P$. vivax. This suggests that in submicroscopic infections, the relative contribution of the loss of unparasitized cells to malarial anaemia is likely much greater than that seen in higher parasitaemia infections.

The mechanisms mediating the loss of unparasitized cells at such low parasitaemias remain incompletely understood. In malaria volunteer infection studies, despite the low parasite counts, participants still experience a significant inflammatory response, with elevated levels of IFN- $\gamma$ and IL-6 [65-67] potentially contributing to inhibition of erythropoiesis [68]. Additional contributors to the loss of unparasitized cells in acute clinical malaria include haemolysis, decreased red blood cell deformability, antibody and complement binding to erythrocytes, loss of complement regulatory proteins on the surface of unparasitized erythrocytes [69] and increase in splenic size [70] with associated splenic clearance of uninfected erythrocytes [71]. However, the role of these processes in low-parasitaemia infections such as volunteer infection studies has been more difficult to define [16].

This study had a number of limitations. First, there was substantial heterogeneity between and within the individual malaria volunteer infection studies, including the drug used, the day of treatment, and the study duration, making it difficult to account for factors associated with haemoglobin loss. Second, in the P. vivax infection studies, the calculation of total parasite burden prior to antimalarial treatment did not account for parasite sequestration. Recent studies have suggested that in chronic $P$. vivax infection, a very high proportion of parasitized erythrocytes are sequestered in the spleen [52], and it has also been shown that splenic accumulation may occur even in early P. vivax infection [70]. It is possible that this may in part explain the low contribution of peripheral parasitized cells to the malaria-attributable erythrocyte loss, in this study and in others [14]. Finally, this study was conducted in malaria-naïve healthy adults, and these data may not be applicable to children, or to adults in malaria-endemic regions where immunity maybe present.

In summary, this study demonstrates that a small but statistically significant fall in haemoglobin occurs in experimental malaria infection, despite parasitaemias that are only just at the level of microscopic detection. This study adds to studies from endemic regions reporting a significant burden of anaemia from asymptomatic and submicroscopic infections, highlighting the importance of treating these groups to reduce the overall burden of anaemia. Finally, this detailed description of the expected haemoglobin loss in malaria volunteer infection studies can be used as a baseline against which to compare the haemoglobin losses that may occur when new antimalarial drugs are evaluated in this model.

\section{Abbreviations}

ANOVA: Analysis of variance; AUC: Area under the curve; EOS: End of study; HB-FF: Fractional fall in haemoglobin; HREC: Human research ethics committee; IBSM: Induced blood-stage malaria; IFN: Interferon; IQR: Interquartile range; MMV: Medicines Malaria Venture; Pf3D7: 3D7 strain of $P$. falciparum; PfK13: K13 artemisinin-resistant strain of P. falciparum; PMR: Parasite multiplication rate; PP: Peak parasitaemia; PP Pre: Pre-treatment peak parasitaemia; PRR: Parasite reduction ratio; $\mathrm{PRBC}$ : Parasitized red blood cell; qPCR: Quantitative Polymerase Chain Reaction; RBC: Red blood cell; RCC: Red cell count; RNA: Ribonucleic acid; SD: Standard deviation; TPB Pre: Pre-treatment total parasite burden; URBC: Unparasitized red blood cell; VIS:Volunteer infection studies.

\section{Supplementary Information}

The online version contains supplementary material available at https://doi. org/10.1186/s12936-021-04003-7.

Additional file 1. Additional tables.

\section{Acknowledgements}

The authors would like to thank the volunteers who participated in the studies, the Malaria Venture for encouraging investigator-driven research, and Cadila Healthcare Ltd and Merck Ltd for approval to use their data.

\section{Authors' contributions}

SDW, LM, JSM and BEB contributed to the design of the study. SDW, JW, LM, $J S M$ and BEB participated in the implementation of the study and/or analysis of results. SDW, ML, SC, JJM, JSM and BEB participated in writing the manuscript. All authors read and approved the final manuscript.

\section{Funding}

QIMR Berghofer Medical Research Institute, Medicines for Malaria Venture, Cadila Healthcare Ltd and Merck Ltd sponsored and funded the studies. JSM received funding from a National Health and Medical Research Council of Australia (NHMRC) program Grant (1132975). JSM is also supported by a NHMRC Practitioner Fellowship.

Availability of data and materials

The datasets used and/or analysed during the current study are available from the corresponding author on reasonable request.

\section{Declarations}

Ethics approval and consent for participate

Ethical approval for all studies was given by the QIMR Berghofer Human Research Ethics Committee.

Consent for publication

Not applicable. 


\section{Competing interests}

The authors declare that they have no competing interests.

\section{Author details}

${ }^{1}$ QIMR Berghofer Medical Research Institute, 300 Herston Road, Brisbane, QLD 4006, Australia. ${ }^{2}$ Centre of Defence Pathology, Royal Centre for Defence Medicine, Joint Hospital Group, ICT Building, Birmingham Research Park, Vincent Drive, Birmingham, UK. ${ }^{3}$ Present Address: Clinical Sciences Department, Liverpool School of Tropical Medicine, Pembroke Place, Liverpool, UK. ${ }^{4}$ Medicines for Malaria Venture, 20 Route de Pre-Bois, PO Box 1826, 1215 Geneva, Switzerland. ${ }^{5}$ Present Address: Laboratory of Malaria Immunology and Vaccinology, NIAID, National Institutes of Health, Bethesda, USA. ${ }^{6}$ Present Address: The Peter Doherty Institute for Infection and Immunity, The University of Melbourne and the Royal Melbourne Hospital, Melbourne, VIC, Australia.

Received: 15 September 2021 Accepted: 1 December 2021 Published online: 20 December 2021

\section{References}

1. WHO. World Malaria Report 2020. Geneva: World Health Organization; 2020.

2. WHO. The potential impact of health service disruptions on the burden of malaria 2020. Geneva: World Health Organization; 2020.

3. Douglas NM, Lampah DA, Kenangalem E, Simpson JA, Poespoprodjo JR, Sugiarto P, et al. Major burden of severe anemia from non-falciparum malaria species in Southern Papua: a hospital-based surveillance study. PLoS Med. 2013;10:e1001575.

4. Cohee LM, Opondo C, Clarke SE, Halliday KE, Cano J, Shipper AG, et al. Preventive malaria treatment among school-aged children in sub-Saharan Africa: a systematic review and meta-analyses. Lancet Glob Health. 2020;8:e1499-511.

5. Gaston RT, Ramroop S, Habyarimana F. Joint modelling of malaria and anaemia in children less than five years of age in Malawi. Heliyon. 2021;7:e06899.

6. von Seidlein L, Olaosebikan R, Hendriksen ICE, Lee SJ, Adedoyin OT, Agbenyega T, et al. Predicting the clinical outcome of severe falciparum malaria in african children: findings from a large randomized trial. Clin Infect Dis. 2012;54:1080-90.

7. Schellenberg D, Schellenberg JRMA, Mushi A, de Savigny D, Mgalula L, Mbuya C, et al. The silent burden of anaemia in Tanzanian children: a community-based study. Bulletin World Health Organ. 2003;81:581-90.

8. de Mast Q, van Dongen-Lases EC, Swinkels DW, Nieman A-E, Roestenberg $M$, Druilhe $P$, et al. Mild increases in serum hepcidin and interleukin-6 concentrations impair iron incorporation in haemoglobin during an experimental human malaria infection. Br J Haematol. 2009;145:657-64.

9. Sumbele IUN, Kimbi HK, Ndamukong-Nyanga JL, Nweboh M, Anchang-Kimbi JK, Lum E, et al. Malarial anaemia and anaemia severity in apparently healthy primary school children in urban and rural settings in the Mount Cameroon area: cross sectional survey. PLoS One. 2015;10:e0123549.

10. Pava Z, Burdam FH, Handayuni I, Trianty L, Utami RAS, Tirta YK, et al. Submicroscopic and asymptomatic Plasmodium parasitaemia associated with significant risk of anaemia in Papua Indonesia. PLoS One. 2016;11:e0165340.

11. Lufungulo Bahati Y, Delanghe J, Bisimwa Balaluka G, Sadiki Kishabongo A, Philippé J. Asymptomatic submicroscopic Plasmodium infection is highly prevalent and is associated with anemia in children younger than 5 Years in South Kivu/Democratic Republic of Congo. Am J Trop Med Hyg. 2020;102:1048-55.

12. Jakeman GN, Saul A, Hogarth WL, Collins WE. Anaemia of acute malaria infections in non-immune patients primarily results from destruction of uninfected erythrocytes. Parasitology. 1999;119:127-33.

13. Price RN, Simpson JA, Luxemburger C, Hkirjaroen L, Chongsuphajaisiddhi T, White NJ. Factors contributing to anemia after uncomplicated falciparum malaria. Am J Trop Med Hyg. 2001;65:614-22.

14. Collins WE, Jeffery GM, Roberts JM. A retrospective examination of anemia during infection of humans with Plasmodium vivax. Am J Trop Med Hyg. 2004;68:410-2.
15. Narsaria N, Mohanty C, Das BK, Mishra SP, Prasad R. Oxidative stress in children with severe malaria. J Trop Pediatr. 2012;58:147-50.

16. Oyong DA, Kenangalem E, Poespoprodjo JR, Beeson JG, Anstey NM, Price $\mathrm{RN}$, et al. Loss of complement regulatory proteins on uninfected erythrocytes in vivax and falciparum malaria anemia. JCI Insight. 2018;3:e124854.

17. Barber BE, Grigg MJ, Piera K, Amante FH, William T, Boyle MJ, et al. Antiphosphatidylserine immunoglobulin $\mathrm{M}$ and immunoglobulin $\mathrm{G}$ antibodies are higher in vivax than falciparum malaria, and associated with early anemia in both species. J Infect Dis. 2019;220:1435-43.

18. Lamikanra AA, Theron M, Kooij TWA, Roberts DJ. Hemozoin (malarial pigment) directly promotes apoptosis of erythroid precursors. PLoS ONE. 2009;4:8446.

19. Panichakul T, Payuhakrit W, Panburana P, Wongborisuth C, Hongeng S, Udomsangpetch R. Suppression of erythroid development in vitro by Plasmodium vivax. Malar J. 2012;11:173.

20. Giribaldi G, Ulliers D, Schwarzer E, Roberts I, Piacibello W, Arese P. Hemozoin- and 4-hydroxynonenal-mediated inhibition of erythropoiesis. Possible role in malarial dyserythropoiesis and anemia. Haematologica. 2004;89:492-3

21. Casals-Pascual C, Kai O, Cheung JOP, Williams S, Lowe B, Nyanoti M, et al. Suppression of erythropoiesis in malarial anemia is associated with hemozoin in vitro and in vivo. Blood. 2006;108:2569-77.

22. Muriuki JM, Mentzer AJ, Mitchell R, Webb EL, Etyang AO, Kyobutungi C, et al. Malaria is a cause of iron deficiency in African children. Nat Med. 2021;27:653-8.

23. Jauréguiberry S, Ndour PA, Roussel C, Ader F, Safeukui I, Nguyen M, et al, Postartesunate delayed hemolysis is a predictable event related to the lifesaving effect of artemisinins. Blood. 2014;124:167-75.

24. Stanisic DI, Mccarthy JS, Good MF. Controlled human malaria infection: applications, advances, and challenges. Infect Immun. 2017:6:e00479-e517.

25. Marquart L, Baker M, O'Rourke P, McCarthy JS. Evaluating the pharmacodynamic effect of antimalarial drugs in clinical trials by quantitative PCR. Antimicrob Agents Chemother. 2015;59:4249-59.

26. Moehrle JJ, Duparc S, Siethoff C, van Giersbergen PLM, Craft JC, ArbeBarnes S, et al. First-in-man safety and pharmacokinetics of synthetic ozonide OZ439 demonstrates an improved exposure profile relative to other peroxide antimalarials. Br J Clin Pharmacol. 2013;75:535-48.

27. Collins KA, Wang CYT, Adams M, Mitchell H, Robinson GJ, Rampton M, et al. A Plasmodium vivax experimental human infection model for evaluating efficacy of interventions. J Clin Invest. 2020;130:2920-7.

28. Phumla S, Cristina D, Hilary J, Grant L, Lubbe W, Elizabeth A, et al. Safety, tolerability, pharmacokinetics, and antimalarial activity of the novel Plasmodium phosphatidylinositol 4-kinase inhibitor MMV390048 in healthy volunteers. Antimicrob Agents Chemother. 2021;64:e01896-e1919.

29. McCarthy JS, Rückle T, Elliott SL, Ballard E, Collins KA, Marquart L, et al. A single-dose combination study with the experimental antimalarials artefenomel and DSM265 to determine safety and antimalarial activity against blood-stage Plasmodium falciparum in healthy volunteers. Antimicrob Agents Chemother. 2019;64:e01371-e1419.

30. Collins KA, Wang CY, Adams M, Mitchell H, Rampton M, Elliott $S$, et al. A controlled human malaria infection model enabling evaluation of transmission-blocking interventions. J Clin Invest. 2018;128:1551-62.

31. McCarthy JS, Abd-Rahman AN, Collins KA, Marquart L, Griffin P, Kümmel $A$, et al. Defining the antimalarial activity of Cipargamin in healthy volunteers experimentally infected with blood-stage Plasmodium falciparum. Antimicrob Agents Chemother. 2021;65:e01423-e1520.

32. Collins KA, Rückle T, Elliott S, Marquart L, Ballard E, Chalon S, et al. DSM265 at 400 milligrams clears asexual stage parasites but not mature gametocytes from the blood of healthy subjects experimentally infected with Plasmodium falciparum. Antimicrob Agents Chemother. 2019;63:e01837-e1918.

33. Collins KA, Abd-Rahman AN, Marquart L, Ballard E, Gobeau N, Griffin P, et al. Antimalarial activity of artefenomel against asexual parasites and transmissible gametocytes during experimental blood-stage Plasmodium vivax infection. J Infect Dis. 2020. https://doi.org/10.1093/infdis/jiaa287.

34. Gaur AH, McCarthy JS, Panetta JC, Dallas RH, Woodford J, Tang L, et al. Safety, tolerability, pharmacokinetics, and antimalarial efficacy of a novel Plasmodium falciparum ATP4 inhibitor SJ733: a first-in-human and induced blood-stage malaria phase $1 \mathrm{a} / \mathrm{b}$ trial. Lancet Infect Dis. 2020:20:964-75. 
35. McCarthy JS, Donini C, Chalon S, Woodford J, Marquart L, Collins KA, et al. A Phase 1, placebo-controlled, randomized, single ascending dose study and a volunteer infection study to characterize the safety, pharmacokinetics, and antimalarial activity of the Plasmodium Phosphatidylinositol 4-Kinase Inhibitor MMV390048. Clin Infect Dis. 2020;71:e657-64.

36. McCarthy JS, Griffin PM, Sekuloski S, Bright AT, Rockett R, Looke D, et al. Experimentally induced blood-stage Plasmodium vivax infection in healthy volunteers. J Infect Dis. 2013;208:1688-94.

37. Odedra A, Mudie K, Kennedy G, Watts RE, Rossignol E, Mitchell H, et al. Safety and feasibility of apheresis to harvest and concentrate parasites from subjects with induced blood stage Plasmodium vivax infection. Malar J. 2021;20:43.

38. First-in-human trial of single ascending dose, multiple ascending dose and malaria challenge model in healthy subjects. Accessed 8 Jun 2021. https:// clinicaltrials.gov/ct2/show/NCT03261401

39. ANZCTR Trial ID: NCT03542149. Phase $1 \mathrm{~b}$ to assess safety, tolerability, pharmacokinetic profile, and antimalarial activity of single doses of Coadministered OZ439and PQP against early Plasmodium falciparum blood stage infection in healthy adult volunteers. 2018.

40. ANZCTR Trial ID: ACTRN12619001215112. Open label study using the P. falciparum induced blood stage malaria (IBSM) model to determine the safety and tolerablity and to characterise the antimalarial activity of a single-dose oral administration of ZY-19489. 2019

41. McCarthy JS, Lotharius J, Ruckle T, Chalon S, Phillips MA, Elliott S, et al. Safety, tolerability, pharmacokinetics, and activity of the novel long-acting antimalarial DSM265: a two-part first-in-human phase 1a/1b randomised study. Lancet Infect Dis. 2017;17:626-35.

42. Stanisic DI, Gerrard J, Fink J, Griffin PM, Liu XQ, Sundac L, et al. Infectivity of Plasmodium falciparum in malaria-naive individuals is related to knob expression and cytoadherence of the parasite. Infect Immun. 2016:84:2689-96.

43. Watts RE, Odedra A, Marquart L, Webb L, Abd-Rahman AN, Cascales L, et al. Safety and parasite clearance of artemisinin-resistant Plasmodium falciparum infection: a pilot and a randomised volunteer infection study in Australia. PLoS Med. 2020;17:e1003203.

44. Pasay CJ, Rockett R, Sekuloski S, Griffin P, Marquart L, Peatey C, et al. Piperaquine monotherapy of drug-susceptible Plasmodium falciparum infection results in rapid clearance of parasitemia but is followed by the appearance of gametocytemia. J Infect Dis. 2016;214:105-13.

45. Smith CM, Jerkovic A, Truong TT, Foote SJ, McCarthy JS, McMorran BJ. Griseofulvin impairs intraerythrocytic growth of Plasmodium falciparum through ferrochelatase inhibition but lacks activity in an experimental human infection study. Sci Rep. 2017;7:41975.

46. Griffin P, Pasay C, Elliott S, Sekuloski S, Sikulu M, Hugo L, et al. Safety and reproducibility of a clinical trial system using induced blood stage Plasmodium vivax infection and its potential as a model to evaluate malaria transmission. PLoS Negl Trop Dis. 2016;10:e000139.

47. McCarthy JS, Ruckle T, Djeriou E, Cantalloube C, Ter-Minassian D, Baker M. A Phase II pilot trial to evaluate safety and efficacy of ferroquine against early Plasmodium falciparum in an induced blood-stage malaria infection study. Malar J. 2016;15:469.

48. Wang CYT, Ballard EL, Pava Z, Marquart L, Gaydon J, Murphy SC, et al. AnaIytical validation of a real-time hydrolysis probe PCR assay for quantifying Plasmodium falciparum parasites in experimentally infected human adults. Malar J. 2021;20:181.

49. White NJ, Chapman D, Watt G. The effects of multiplication and synchronicity on the vascular distribution of parasites in falciparum malaria. Trans R Soc Trop Med Hyg. 1992;86:590-7.

50. Wockner LF, Hoffmann I, Rourke P, Mcarthy JS, Marquart L. Comparison of statistical models to estimate parasite growth rate in the induced blood stage malaria model. Malar J. 2017;16:352.

51. Wockner LF, Hoffmann I, Webb L, Mordmüller B, Murphy SC, Kublin JG, et al. Growth rate of Plasmodium falciparum: analysis of parasite growth data from malaria volunteer infection studies. J Infect Dis. 2019:221:963-72.

52. Kho S, Qotrunnada L, Leonardo L, Andries B, Wardani PAl, Fricot A, et al. Evaluation of splenic accumulation and colocalization of immature reticulocytes and Plasmodium vivax in asymptomatic malaria: A prospective human splenectomy study. PLoS Med. 2021;18:e1003632.

53. Bei AK, DeSimone TM, Badiane AS, Ahouidi AD, Dieye T, Ndiaye D, et al. A flow cytometry-based assay for measuring invasion of red blood cells by Plasmodium falciparum. Am J Hematol. 2010;85:234-7.
54. Ekvall H, Premji Z, Björkman A. Chloroquine treatment for uncomplicated childhood malaria in an area with drug resistance: early treatment failure aggravates anaemia. Trans R Soc Trop Med Hyg. 1998;92:556-60.

55. Bloland PB, Lackritz EM, Kazembe PN, Were JBO, Steketee R, Campbell CC. Beyond chloroquine: implications of drug resistance for evaluating malaria therapy efficacy and treatment policy in Africa. J Infect Dis. 1993;167:932-7.

56. Sowunmi A, Gbotosho GO, Happi C, Okuboyejo T, Folarin O, Balogun S, et al. Therapeutic efficacy and effects of artesunate-mefloquine and mefloquine alone on malaria-associated anemia in children with uncomplicated Plasmodium falciparum malaria in southwest Nigeria. Am J Trop Med Hyg. 2009;81:979-86.

57. Sowunmi A, Balogun ST, Gbotosho GO, Happi CT. Effects of amodiaquine, artesunate, and artesunate-amodiaquine on Plasmodium falciparum malaria-associated anaemia in children. Acta Trop. 2009;109:55-60.

58. Grigg MJ, William T, Menon J, Barber BE, Wilkes CS, Rajahram GS, et al. Efficacy of artesunate-mefloquine for chloroquine-resistant Plasmodium vivax malaria in Malaysia: an open-label, randomized, controlled trial. Clin Infect Dis. 2016:62:1403-11.

59. Zwang J, D'Alessandro U, Ndiaye J-L, Djimdé AA, Dorsey G, Mårtensson AA, et al. Haemoglobin changes and risk of anaemia following treatment for uncomplicated falciparum malaria in sub-Saharan Africa. BMC Infect Dis. 2017;17:443.

60. Shaukat AM, Gilliams EA, Kenefic L, Laurens MB, Dzinjalamala FK, Nyirenda $\mathrm{OM}$, et al. Clinical manifestations of new versus recrudescent malaria infections following anti-malarial drug treatment. Malar J. 2012;11:207.

61. Mousa A, Al-Taiar A, Anstey NM, Badaut C, Barber BE, Bassat Q, et al. The impact of delayed treatment of uncomplicated P. falciparum malaria on progression to severe malaria: a systematic review and a pooled multicentre individual-patient meta-analysis. PLoS Med. 2020;17:e1003359.

62. Sumbele IUN, Samje M, Nkuo-Akenji T. A longitudinal study on anaemia in children with Plasmodium falciparum infection in the Mount Cameroon region: prevalence, risk factors and perceptions by caregivers. BMC Infect Dis. 2013;13:123.

63. Kahigwa E, Schellenberg D, Sanz S, Aponte JJ, Wigayi J, Mshinda H, et al. Risk factors for presentation to hospital with severe anaemia in Tanzanian children: a case-control study. Trop Med Int Health. 2002;7:823-30.

64. Simbauranga RH, Kamugisha E, Hokororo A, Kidenya BR, Makani J. Prevalence and factors associated with severe anaemia amongst under-five children hospitalized at Bugando Medical Centre, Mwanza Tanzania. BMC Hematol. 2015;15:13.

65. Hermsen CC, Konijnenberg Y, Mulder L, Loé C, van Deuren M, van der Meer JWM, et al. Circulating concentrations of soluble granzyme $A$ and $B$ increase during natural and experimental Plasmodium falciparum infections. Clin Exp Immunol. 2003;132:467-72.

66. Walther M, Woodruff J, Edele F, Jeffries D, Tongren JE, King E, et al. Innate immune responses to human malaria: Heterogeneous cytokine responses to blood-stage Plasmodium falciparum; Correlate with parasitological and clinical outcomes. J Immunol. 2006;177:5736-45.

67. de Jong GM, McCall MBB, Dik WA, Urbanus RT, Wammes L, Koelewijn $R$, et al. Transforming growth factor-beta profiles correlate with clinical symptoms and parameters of haemostasis and inflammation in a controlled human malaria infection. Cytokine. 2020;125:154838.

68. Perkins DJ, Were T, Davenport GC, Kempaiah P, Hittner JB, et al. Severe malarial anemia: innate immunity and pathogenesis. Int J Biol Sci. 2011;7:1427-42.

69. White NJ. Anaemia and malaria. Malar J. 2018;17:371

70. Woodford J, Gillman A, Jenvey P, Roberts J, Woolley S, Barber BE, et al. Positron emission tomography and magnetic resonance imaging in experimental human malaria to identify organ-specific changes in morphology and glucose metabolism: a prospective cohort study. PLoS Med. 2021;18:e1003567.

71. Safekui I, Gomez ND, Adelani AA, Burte F, Afolabi NK, Akondy R, et al. Malaria induces anemia through CD8+ T cell dependent parasite clearance and erythrocyte removal in the spleen. mBio. 2015;6:e02493-14.

\section{Publisher's Note}

Springer Nature remains neutral with regard to jurisdictional claims in published maps and institutional affiliations. 